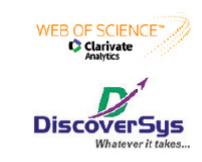

Published by DiscoverSys

\section{The characteristics of neurocognitive function in farmers exposed to chronic pesticides at Banjar Tengah Kelod, Kerambitan, Tabanan, Bali, Indonesia}

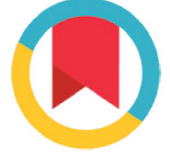

CrossMark

\author{
Dewa Putu Gde Purwa Samatra ${ }^{1 *}$, Ni Luh Putu Dirasandhi Semedi Putri ${ }^{1}$
}

'Department of Neurology, Faculty of Medicine, Universitas Udayana, Sanglah General Hospital, BaliIndonesia

\section{*Corresponding to: Dewa Putu Gde Purwa Samatra; Department of Neurology, Faculty of Medicine, Udayana University, Sanglah General Hospital, Bali- Indonesia; \\ purwa bali@yahoo.com}

Received: 2019-06-11 Accepted: 2019-09-12 Published: 2019-12-01

\section{INTRODUCTION}

Neurocognitive function is a conscious mental activity, such as thinking, remembering, learning, and using language. Neurocognitive function is influenced by several factors, such as biological, socio-economic, and environmental. ${ }^{1}$ One of the much debated environmental factors of concern is the use of pesticides.

Pesticides are all substances or mixtures of chemical or biological substances that aim to repel, kill, and control pests, and regulate plant growth. ${ }^{2}$ The chemical structure of pesticides is divided into four main groups, namely: organophosphate, carbamate, organochlorine, and pyrethrin and pyrethroids. Pesticides have been used extensively in agriculture. Agricultural improvement correlates with increased use of pesticides. Bali is one of the provinces with an increasing agricultural yield. ${ }^{3}$

The pathophysiology of pesticide exposure causes cognitive function impairment is still being debated. A study conducted by Luo and Chen (mean score of 1.5 what scoring was used?) and visuospatial executive functions (mean score of 1 , what scoring system?). The mean memory function score in the organochlorine user group was the highest compared to other groups of pesticide users while the average score of visuospatial function was 1 . The samples of the study using carbamate pesticides had the same average score in both domains of neurocognitive function. The mean score of memory function in pyrethroid user was 2.5 and the average score of executive visuospatial function was 1.

Conclusion: Chronic exposure to the four types of pesticides provided a picture of neurocognitive function impairment, including memory, visuospatial and executive functions. This result did not show clinical significance. The addition of sample size and analytic method studies should be considered for further research.

Keywords: neurocognitive, pesticides, farmers

Cite this Article: Samatra, D.P.G.P., Putri, N.L.P.D.S. 2019. The characteristics of neurocognitive function in farmers exposed to chronic pesticides at Banjar Tengah Kelod, Kerambitan, Tabanan, Bali, Indonesia. Bali Medical Journal 8(3): 587-590. D0l: 10.15562/bmj.v8i3.1533

shows that administration of pesticides containing deltamethrin and carbofuran to mice once a day for 28 days showed a decrease in spatial memory function. A meta-analysis study of 1256 articles by Munoz-Quezada et al. also concluded that there was association between chronic exposure of organophosphates pesticides with decreased neurocognitive function in exposed workers. ${ }^{4}$ Other studies have been conducted on 191 cases with a history of organophosphate pesticide sprayers, namely chlorpyrifos for a minimum of 2 years compared with 189 control group who was never exposed. However, the results of examination of visuospatial, psychomotor, and neurocognitive functions in these two groups did not differ significantly. ${ }^{5}$

Factors that encouraged researchers to do this research are the high use of pesticides in Bali, the theory of neurocognitive function impairment related to long-term use of pesticides which is still controversial, the risk of decreasing quality of life that can be experienced related to neurocognitive 
function impairment, as well as limited research data. This study aims to evaluate the characteristics of neurocognitive function in farmers who were chronically exposed to pesticides.

(Consider adding some brief introductory statements on several tools to assess neurocognitive function, and briefly explain why the Mini-Cog test was chosen for this study.)

\section{MATERIALS AND METHODS}

This study uses a descriptive cross-sectional design with total sampling methods. The study was conducted on $1^{\text {st }}$ January 2019 until $31^{\text {st }}$ January 2019 located in Banjar Tengah Kelod, Kerambitan sub-district, Tabanan district, Bali, Indonesia.

The accessible population in this study was farmers with chronic pesticides users who resided in in Banjar Tengah Kelod, Kerambitan sub-district, Tabanan district during the study period. All farmers who met the eligibility criteria were included as research sample. The inclusion criteria in this study are pesticide users who were farmers aged 40-60 years, had been exposed to pesticides directly for at least the last 2 years, did not use personal protective equipment when using pesticides, and were willing to be included in the research by signing informed consent. While the exclusion criteria are having previous history of neurological diseases such as stroke, epilepsy, brain tumors, Parkinson's, dementia, neuromuscular disease, history of drug use that has an effect on neurocognitive function, and a history of acute intoxication of pesticides. All

\section{Table 1 Characteristics of Samples}

\begin{tabular}{llc}
\hline Characteristics & & Total (\%) \\
\hline $\begin{array}{l}\text { Age (year) } \\
\text { median (min-max) }\end{array}$ & & $55(40-60)$ \\
& $40-55$ & \\
& $>55$ & $31(51.7)$ \\
Gender & Male & $29(48.3)$ \\
& Female & $24(40)$ \\
Formal Education (year) & Education $\leq 6$ & $36(60)$ \\
& Education $>6$ & $44(73.3)$ \\
Time of Exposure & & $16(26.7)$ \\
median (min-max) & & $10(2-40)$ \\
Types of Pesticides & Organophosphate & \\
& Organochorine & $33(55.0)$ \\
& Pyrethroid & $14(23.3)$ \\
& Carbamate & $4(6.7)$ \\
Mini-Cog score & & $9(15.0)$ \\
median (min-max) & & $2(1-5)$ \\
& Impaired & $30(50)$ \\
& Normal & $30(50)$ \\
\hline
\end{tabular}

research samples were interviewed by the research team regarding demographic aspects, pesticide use activities, and neurocognitive function tests. history of exposure to pesticides directly, either through the process of mixing pesticides, spraying pesticides, and cleaning pesticide applicator tools in a minimum period of 2 years. ${ }^{6}$ Neurocognitive function is the thinking and mental abilities of the research subject consisting of five cognitive domains which are attention, language, memory, visuospatial, and executive. Neurocognitive function was examined using a Mini-Cog test. Mini-Cog test scores of less than 3 indicate impaired neurocognitive function. A Mini-Cog test scores of more or equal to 3 indicate normal neurocognitive function. The data collected were analyzed using SPSS version 21.0 for Windows.

\section{RESULTS}

This study had a total of 60 samples. Demographic characteristics of the research samples are presented in Table 1. This study consisted of 60 samples, 36 samples (60\%) were women and 24 samples (40\%) were men. The median age of the study sample was 55 year-old. Seventy-three percent of the research samples has an educational background of less than six years. The longest exposure to pesticides was 40 years. Most of the participants used organophosphate pesticides. The Mini-Cog score range obtained by the research samples were between 1 and 5 .

We evaluated the neurocognitive function of the samples based on the type of pesticide used. Most of the samples who experienced neurocognitive impairment used organophosphate pesticides $(60 \%)$, followed by organochlorine (20\%), carbamate $(13.3 \%)$, and pyrethroid $(6.7 \%)$. The different proportions between samples with impaired and normal neurocognitive function based on the type of pesticide used did not show clinical significance. Characteristics of neurocognitive function disorders based on the type of pesticide used are presented in Table 2.

We also evaluated the mean of Mini-Cog scores according to each neurocognitive function domain based on the type of pesticide used. Mini-Cog can evaluate memory function with maximum score of 3 and executive visuospatial functions with maximum score of 2 .

Organophosphate users experienced neurocognitive impairment in both memory domain (mean score of 1.5) and visuospatial executive function (mean score of 1). The mean memory function score in the organochlorine user group was the highest compared to other groups
Chronic pesticide exposure is defined as a 
Table 2 Characteristics of neurocognitive function impairment based on the type of pesticide

\begin{tabular}{lcc}
\hline \multicolumn{1}{c}{ Type of Pesticide } & \multicolumn{2}{c}{ Neurocognitive Function $(\mathbf{n}, \%)$} \\
& Impaired & Normal \\
\hline Organophosphate & $18(60.0)$ & $15(50.0)$ \\
Organochorine & $6(20.0)$ & $8(26.7)$ \\
Carbamate & $4(13.3)$ & $5(16.7)$ \\
Pyrethroid & $2(6.7)$ & $2(6.7)$ \\
\hline
\end{tabular}

Table 3 Neurocognitive function domain mean score based on the type of pesticide

\begin{tabular}{|c|c|c|}
\hline \multirow{2}{*}{ Pesticide type } & \multicolumn{2}{|c|}{$\begin{array}{l}\text { Mean neurocognitive score } \\
\text { OR Mean mini-cog score }\end{array}$} \\
\hline & Memory & Executive Visuospatial \\
\hline Organophosphate & 1.5 & 1 \\
\hline Organochorine & 3 & 1 \\
\hline Carbamate & 2 & 2 \\
\hline Pyrethroid & 2.5 & 1 \\
\hline
\end{tabular}

of pesticide users. While the average score of visuospatial executive function was 1 . The samples of the study using carbamate type pesticides had the same average score in both domains of neurocognitive function. The mean score of memory function in pyrethroid user samples was 2.5 and the average score of executive visuospatial function was 1 . The average score of each domain is presented in Table 3.

\section{DISCUSSION}

Pesticides have been used extensively in agriculture. Acute pesticides exposure has been shown to cause side effects on physical and mental health while chronic pesticides exposure has not been fully concluded. Neurocognitive function impairment is one of the reported health side effects that may occur due to chronic pesticides exposure.

All samples of this study were users of chronic pesticides. Samples used four types of pesticides, which are organophosphate, organochlorine, carbamate, and pyrethroid. The results of this study indicated that the subjects who experienced neurocognitive impairment mostly were organophosphate users, followed by organochlorine, carbamate, and pyrethroid users.

This study evaluated neurocognitive function in each type of pesticide used. Fifty-four percent of subjects using organophosphate pesticides experience neurocognitive dysfunction. The average Mini-Cog score in this group was 2.58. The pathophysiology of organophosphates causing neurocognitive dysfunction had been widely described in previous studies. Organophosphates were explained to cause vascular dysfunction through atherosclerosis. This theory is supported by the results of Li's 2015 study which provided rats with isocarbophos pesticides for 16 weeks found dysfunction of the cerebral arteries causing impairment in learning and memory. ${ }^{7}$ The association of vascular dysfunction with hippocampal damage is also supported by a study using mice with isocarbophos exposure. Isocarbophos provoked many histological changes in the hippocampus, such as neuronal loss, neuronal shrinkage, edema in hippocampal pyramidal cells, inflammatory cell infiltration and excessive astroglia cell proliferation. Hippocampal neurons also appeared smaller and the membrane structure was damaged with a shrinking core and chromatin aggregated to the edges. Increased number of Golgi bodies, edema and mitochondrial damage to the hippocampus. ${ }^{7}$ The Mini-Cog evaluation found that organophosphate users experienced neurocognitive dysfunction in both the memory and visuospatial executive function domains. This result is in accordance with the pathophysiology of organophosphates which causes hippocampal damage, which is an important component in the process of memory formation. This is also in accordance with previous studies that found organophosphates cause disturbances in memory function, spatial learning, and executives. ${ }^{8,9}$

The organochlorine user group also showed neurocognitive impairment especially in the visuospatial executive function, whereas the average score of the organochlorine user memory function reached normal values. A cross-sectional analytic study was conducted in the United States in 644 elderly aged 66-85 years of age to determine the association of organochlorine exposure and neurocognitive function. This study evaluated six types of organochlorine derivatives, namely $p, p^{\prime}$-dichlorodiphenyltrichloroethane (DDT), p, p'dichlorodiphenyldichloroethylene (DDE), transnonachlor, oxychlordane, heptachlor epoxide, and $\beta$-hexachlorocyclohexane. Neurocognitive function is assessed using the Digit-Symbol Substitution Test. The results of this study indicated a significant inverse association between serum organochlorine levels and neurocognitive function. DDT organochlorine derivatives had risk 6.5 times for decreasing neurocognitive function. Digit-Symbol Substitution Test is a significant examination to evaluate motor speed, attention, visuospatial perception including the ability to draw and write, and evaluate executive functions, in this case are planning and strategy making. ${ }^{9}$ 
Carbamate users also showed decrease in neurocognitive function in this study, especially in the memory function. Whereas the domain of visuospatial executive functions showed normal mean score. The mean of mini-cog test total score was 2.78. Similar results were found in previous studies in New Delhi in 2010 on mice that received $10 \mathrm{mg} / \mathrm{kg}$ body weight of carbamate exposure for 30 days and obtained decrease in memory function through elevated examination plus a maze learning task. ${ }^{10}$

The mean of Mini-Cog total score in the pyrethroid user group was 2.75 and the mean of memory function and visuospatial score were below the normal score. Similar results were reported in a previous study in 2017 on 120 mosquito spraying officers using pyrethroid pesticides. Neurocognitive function disorders were obtained based on several examinations namely Boston Naming Test, Digit span test forward, Digit span test backward, Symboldigit test, Serial digit learning, and Matching to sample. These modalities of examination were to evaluate the neurocognitive function in a complex manner, including attention, memory, executive, and visuospatial.

\section{CONCLUSION}

Chronic exposure to the four types of pesticides, namely organophosphate, organochlorine, carbamate, and pyrethroid provided a picture of neurocognitive function impairment, including memory, visuospatial and executive functions. This result did not show any clinical significance. The addition of sample size and analytic studies should be considered for further research.

\section{CONFLICT OF INTEREST}

There were no financial supports or relationship between authors and any organization that could pose any conflict of interests on this article.

\section{ACKNOWLEDGMENTS}

None

\section{REFERENCES}

1. Arciniegas DB, Anderson CA, Filley CM. Behavioral Neurology \& Neuropsychiatry. New York: Cambridge University Press; 2013.
2. WHO. Biological Monitoring of Chemical Exposure in the Workplace. Geneva: World Health Organization; 1996.

3. Badan Pusat Statistik. Laporan Bulanan Data Sosial Ekonomi. Edisi 94. Jakarta: Badan Pusat Statistik; 2018.

4. Munoz-Quezada MT, Lucero B, Iglesias V, Munoz MP, Achu E, Cornejo C, Concha C. Brito AM, Villabos M. Chronic exposure to organophosphate (OP) pesticides and neuropsychological functioning in frm workers : a review. Int J Environ Health Res' 2017. 27(1): 82-93.

5. Steenland K, Dick RB, Howell RJ, Chrislip DW, Hines CJ, Reid TM, Lehman E, Laber P, Krieg EF, Knott JC. Neurologic function among termiticide applicators exposed to chlorpyrifos. Environ Health Perspect; 2000. 108(4): 293300.

6. Kementrian Kesehatan. Peraturan Menteri Kesehatan Nomor 1350/Menkes/SK/XII/2001 tentang Pestisida.

7. Li G, Kim C, Kim J, Yoon H, Zhou H, Kim J. Common Pesticide, Dichlorodiphenyltrichloroethane (DDT), Increases Amyloid-beta Levels by Impairing the Function of ABCA1 and IDE: Implication for Alzheimer's Disease. Journal of Alzheimer's disease : JAD. 2015;46(1):109-2

8. Kim KS, Lee YM, Lee WH, Jacobs DR, Lee DH. Associations between organochlorine pesticides and cognition in U.S. elders: National Health and Nutrition Examination Survey 1999-2002. Environ Int. 2015;75:87-92.

9. Jaeger J. Digit Symbol Substitution Test. The Case for Sensitivity Over Specificity in Neuropsychological Testing. J Clin Psychopharmacol; 2018. 38(5): 513-519.

10. Yadav CS, Kumar V, Suke SG, Ahmed RS, Mediratta PK, Banerjee BD. 2010. Propoxurinduced acetylcholine esterase inhibition and impairment of cognitive function: attenuation by Withania somnifera. Indian J Biochem Biophys. ; 2010. 47(2):117-20

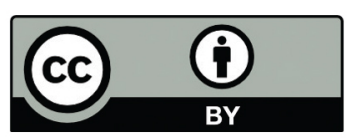

This work is licensed under a Creative Commons Attribution 